\title{
Remarkable Role of Experimental Olefin-Maleic-Anhydride Copolymer Based Compatibilizing Additives in Blends of Waste PET Bottles and Polyamide
}

\author{
B. $\operatorname{Nagy}^{1} \cdot$ C. S. $\operatorname{Varga}^{1} \cdot$ K. Kontos ${ }^{1} \cdot$ L. Simon-Stöger ${ }^{1}$ \\ Received: 2 March 2020 / Accepted: 20 September 2020 / Published online: 10 October 2020 \\ (c) The Author(s) 2020
}

\begin{abstract}
Over the past 50 years demand for plastics drastically increased worldwide resulting in plastic wastes causing serious environmental problems. The main market sector of European plastics industry is the packaging industry most of which are polyolefins and poly(ethylene-terephtalate). In the EU, 29.1 million tonnes of plastic waste were collected in 2018, of which 32.5\% was recycled, $42.6 \%$ was recovered for energy, and 24.9\% was landfilled (Plastics-the Facts, 2019). Although landfilling of collected waste in the EU is steadily declining, there is still too much unused waste. Polymer blends based on waste resources can solve the issues of recycling. The main purpose of the research was to produce polymer blends from waste based PET that have appropriate mechanical properties and rheological behaviour as well in order to find application areas where product requirements are not strict. Blends containing waste based PET were extrusion moulded and calenderd producing extrusion strings and films. Rheological and tensile properties of three types of PET/engineering thermoplastic blends (PET/PC, PET/PA and PET/ABS) were studied. Miscibility of components of the blends is limited leading to weak mechanical properties such as low tensile strength and/or elongation at break. Due to that phenomenon compatibilizing additives are also required. As compatibilizing additives olefin-maleic-anhydride copolymer based additives have been used in our experiments. Structure of additives differed from each other both in ratio and length of carbon chains of compounds linked to maleic-anhydride groups. Blends have been studied with PET content ranging from 10 to $90 \%$. As an outstanding result improving of mechanical properties was achieved, for example almost $40 \%$ growth was observed in elongation at break of extruded $80 / 20$ PET/PA blends in the presence of $0.2 \%$ compatibilizing additive compared to the sample without additive, meanwhile its strength has also improved.
\end{abstract}

Electronic supplementary material The online version of this article (https://doi.org/10.1007/s12649-020-01253-5) contains supplementary material, which is available to authorized users.

B. Nagy

nagy.bianka@mk.uni-pannon.hu

1 Institutional Department of MOL Hydrocarbon and Coal Processing, University of Pannonia, Veszprém 8200, Hungary 


\section{Graphic Abstract}

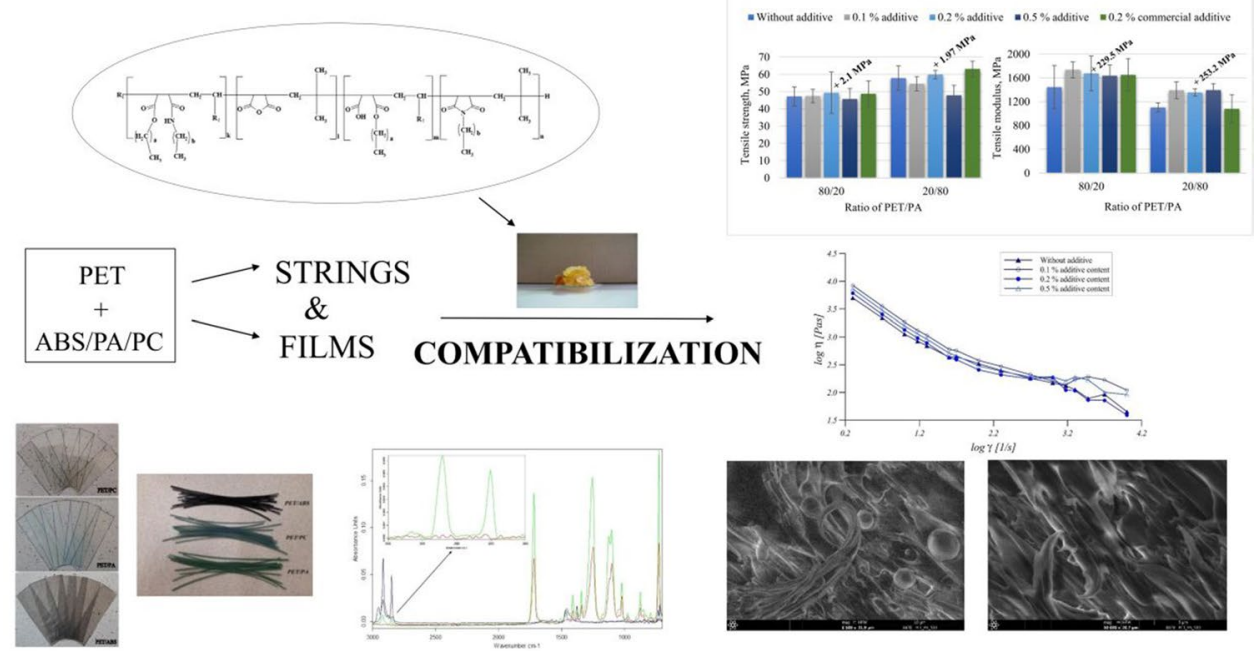

Keywords Blends $\cdot$ Compatibilizing additives $\cdot$ Polymer processing $\cdot$ Recycling

\section{Abbreviations}

PET Polyethylene terephthalate

PA Polyamide

PC Polycarbonate

ABS Acrylonitrile Butadiene Styrene

PP Polypropylene

LDPE Low-Density Polyethylene

PS Polystyrene

FT-IR Fourier-transform infrared spectroscopy

HDPE High-density polyethylene

MFI Melt Flow Index

MVR Melt Volume Rate

A1 Additive 1

A2 Additive 2

A3 Additive 3

SEM Scanning Electron Microscope

\section{Statement of Novelty}

Production of polymer blends based on waste resources can contribute to the solution of the urgent recycling issues. Experimental olefin-maleic-anhydride copolymer based additive have been used in PET/PA, PET/PC and PET/ABS blends for improving miscibility between the phases. The main characteristics of the additive are the viscous consistency as a result it can be used in masterbatch form and there is possibility to set the ratio of functional group resulting in distinct additive efficiency. The use of the experimental additive provides an opportunity to process waste PET with other engineering plastics (such as polyamide) and to use the resulting composite in areas where mechanical requirements are not strict. The effect of additive can be influenced by selecting the matrix material.

\section{Introduction}

Over the recent few decades significant innovation has begun in the field of polymer blending because polymer blends considered as a mechanical mixture of two or more components are novel materials that can be able to carry individual properties of the raw materials and also reveal some synergistic effects [1].

Taking advantage of compatibilization technology high performance polymer blends have been introduced to the market and have appeared in many areas of everyday life thanks to their successful application [2, 3]. For instance, with development of the PC/ABS blend one of the most successful polymer blends have been commercialized, that is widely used in the automotive and electronics industries [2]. However only certain types of polymers can be mixed with each other since there are limited miscibility between the components in the most cases. Each polymer blend has a miscibility limit that defines the extent of the miscibility range [4]. The lack of mutual solubility of components of blends can cause weaker mechanical properties than those of the starting materials. One reason for that may be the poor interfacial interaction. When producing blends with appropriate mechanical properties, the greatest attention 
should be paid to improving the degree of miscibility. One of the possibilities to eliminate the mentioned phenomenon is to apply compatibilizing additives with different structures that are able to create a "bridge" between the two polymers, therefore influence the interfacial interactions in an advantageous way.

Besides producing new polymer blends with exceptional properties, blending of polymers also plays an important role in waste management. Namely different types of waste polymer recyclates can be processed together or partially mixed with original raw materials using compatibilizing additives, thus blending techniques allow a smaller use of commercial raw materials [3].

In 2018, world production of plastics reached almost 360 million tonnes, in Europe (EU28 + NO/CH) it was almost 62 million tons [5]. The consequence of increasing user demand for plastics and at the same time its major disadvantage is the mass production of plastic waste. Although recycling of plastic waste in the EU has been increasing rapidly since 2006, in $201825 \%$ of plastic waste was still landfilled. In Europe (EU28 + NO/CH) 32.5\% of the 29.1 million tonnes of plastic waste collected in 2018 was recycled ( $81 \%$ within the EU, $19 \%$ in non-EU countries), $42.6 \%$ was recovered for energy and $24.9 \%$ was dumped [5]. The legislation enforced to protect the environment require the development of more and more up-to-date recycling methods. Mechanical recycling can be one of the most economical, feasible and ecoefficient solutions for the recycling of plastic waste [6]. In Europe, packaging is the leading market sector of the plastics industry, with a significant proportion of different types of polyethylenes, polypropylenes and poly(ethylene-terephtalate) $[7,8]$. Poly (ethylene-terephthalate) is a partially crystalline thermoplastic polyester with excellent mechanical properties and transparency. In 1973, Nathaniel Wyeth patented PET bottles, which were spread explosively as packaging for disposable soft drinks in the 1980s [9]. Regarding the use of PET bottles, soft drinks and mineral water bottles make up the largest proportion, but it can be found in a wide range of packaging, such as food, cosmetics and pharmaceutical industries as well. In recent years, numerous studies have focused on the blends containing PET and other thermoplastic polymers, such as the characteristics of blends of PET/PP [10], PET/LDPE [11], PET/ABS [12, 13], PET/PS [14], PET/PA [15] and PET/PC [16, 17]. Hydrolytic and thermal degradation of polyester macromolecules is a major problem in the production of PET containing blends [18]. That problem in PET/engineering thermoplastic blends was primarily due to the fact that the polymer blend is processed at a temperature of about $260{ }^{\circ} \mathrm{C}$ or higher because PET has a high melting temperature which increases the rate of degradation of macromolecular chains $[18,19]$. The other problem was the incompatibility of components that can lead to weak interfacial interaction hence blends have weak mechanical properties as well [19]. Therefore, focus of the experiment was waste based poly(ethylene-terephtalate) which was one of the raw materials of PET/engineering thermoplastic blends produced. In the present research properties and compatibilization with experimental olefinmaleic-anhydride copolymer based additives of different composition of PET/engineering thermoplastic blends were investigated. The main motivation of the present research is to make waste PET mechanically recyclable in the presence of different types of engineering plastics. Quality-enhanced blends of PET and engineering plastic (e.g. PET/PA) with an effective compatibilizer can be used in areas where the mechanical requirements are not strict and on the other hand it is possible to replace a smaller proportion of raw materials of commercially available engineering plastic (e.g. PA) products with waste PET. Thus, our purpose is to produce waste based blends with appropriate mechanical properties and easily processable flow properties as well.

\section{Experimental}

\section{Materials and Characterization}

Two different types of waste based poly(ethylene-terephtalate) were used in our experiment. One was a real industrial waste based PET regranulate analyzed by FT-IR spectroscopy indicating polyolefin impurities coming from cap and label of PET bottles, the other waste material was PET bottles without any polyolefins. The latter raw material was collected at Department of MOL Hydrocarbon and Coal Processing. Selectively collected PET bottles were homogenized by extrusion molding after grinding and pelletized. Prior to extrusion molding, PET chips were conditioned at $60{ }^{\circ} \mathrm{C}$ for $16 \mathrm{~h}$. Spectra of the two PET materials showed the same functional groups otherwise, the most characteristics peak appeared at $1718 \mathrm{~cm}^{-1}$ belonging to the stretching vibration of carbonyl groups in the polymer chain ("Appendix 1").

\section{Engineering Thermoplastics}

The engineering thermoplastics were commercial, ABS (POLYLAC PA-737, density $\left(23^{\circ} \mathrm{C}\right): 1.04 \mathrm{~g} / \mathrm{cm}^{3}$; MFI $\left(200{ }^{\circ} \mathrm{C}, 5 \mathrm{~kg}\right.$ ): $\left.2.6 \mathrm{~g} / 10 \mathrm{~min}\right)$, PC (PANLITE L-1225L, density $\left(23{ }^{\circ} \mathrm{C}\right): 1.20 \mathrm{~g} / \mathrm{cm}^{3}$; MVR $\left(300{ }^{\circ} \mathrm{C}, 1.2 \mathrm{~kg}\right): 18$ $\mathrm{cm}^{3} / 10 \mathrm{~min}$ ) and PA (DOMAMID 6AV, density $\left(23^{\circ} \mathrm{C}\right.$ ): $1.14 \mathrm{~g} / \mathrm{cm}^{3}$; MVR $\left.\left(275^{\circ} \mathrm{C}, 5 \mathrm{~kg}\right): 165 \mathrm{~cm}^{3} / 10 \mathrm{~min}\right)$.

\section{Polyolefins}

Matrix materials of masterbatches were polyolefins, two different types of polypropylene (MOPLEN EP300K; density $\left(23{ }^{\circ} \mathrm{C}\right): 0.9 \mathrm{~g} / \mathrm{cm}^{3}$; MFR $\left(230{ }^{\circ} \mathrm{C}, 2.16 \mathrm{~kg}\right): 4.0 \mathrm{~g} / 10 \mathrm{~min}$, 
and BRASKEM H734-52; density ( $23^{\circ} \mathrm{C}$ ): $0.9 \mathrm{~g} / \mathrm{cm}^{3}$; MFR $\left(230{ }^{\circ} \mathrm{C}, 2.16 \mathrm{~kg}\right.$ ): $52 \mathrm{~g} / 10 \mathrm{~min}$ ) and a HDPE (HOSTALEN GC7260; density $\left(23{ }^{\circ} \mathrm{C}\right): 0.960 \mathrm{~g} / \mathrm{cm}^{3}$; MFR $\left(190{ }^{\circ} \mathrm{C}\right.$, 2,16 kg): $8.0 \mathrm{~g} / 10 \mathrm{~min}$ ).

\section{Compatibilizing Additives}

As compatibilizing additives four distinct types of additives were applied, one was the commercial maleic-anhydride grafted polypropylene (LICOMONT AR504) supplied by Clariant $\mathrm{GmbH}$ (density: $0.91 \mathrm{~g} / \mathrm{cm}^{3}$, acid number: $41 \mathrm{mg} \mathrm{KOH} / \mathrm{g}$ sample), the other three additives [20] were experimental olefin-maleic-anhydride copolymer based types ("Appendix 2") synthesized at Department of MOL Hydrocarbon and Coal Processing used in the form of masterbatches.

Infrared spectroscopy was required to determine the presumable functional groups of the olefin-maleic-anhydride copolymer based additives used, FT-IR spectra were shown in "Appendix 3". Between the 3000 and $2800 \mathrm{~cm}^{-1}$ the stretching vibrations of the methyl and methylene groups appeared, the first two peaks belong to the asymmetric vibrations, the last two are the symmetric stretching vibrations of the groups. Wavenumber range of $1900-1650 \mathrm{~cm}^{-1}$ ("Appendix 4") contained vibrations of anhydride and imide rings (1860-1778 $\mathrm{cm}^{-1}$ ), half-ester, esteramide and imide groups $\left(1720-1660 \mathrm{~cm}^{-1}\right)$. The differences in the additive structures were manifested in the ratio of the anhydride, half-ester, ester-amide and imide functional groups. While additive "A1" had higher ratio of anhydride, "A2" had higher ester-amide and imide ratio, and "A3" had higher ratio of half-ester functional group. Table 1 summarizes typical properties of the experimental additives.

Before preparing blends with compatibilizing additives, MFI and tensile properties of masterbatches were determined whether the additives had any softening effect.

MFI measurements were carried out at $230{ }^{\circ} \mathrm{C}$ according to safety data sheet of the polymer. Masterbatch containing additive "A1", viscosity decreased compared to the

Table 1 Typical properties of the experimental olefin-maleic-anhydride copolymer based additives

\begin{tabular}{lllc}
\hline Feature & A1 & A2 & A3 \\
\hline $\begin{array}{l}\text { Acid number, mg } \\
\text { KOH/g sample }\end{array}$ & 46.4 & 37.9 & 36.7 \\
$\begin{array}{l}\text { Saponification number, } \\
\text { mg KOH/g sample }\end{array}$ & 157.3 & 72.5 & 101.3 \\
Ratio of the functional groups & & \\
Anhydride & 0.2437 & 0.1135 & 0.1115 \\
Half-ester & 0.3621 & 0.3205 & 0.3926 \\
Ester-amide & 0.1971 & 0.2830 & 0.2480 \\
Imide & 0.1971 & 0.2830 & 0.2480 \\
\hline
\end{tabular}

corresponding polyolefin (except the masterbatch containing Braskem type PP), resulting in increase in MFI values, so two of the masterbatches had softening effect. Among masterbatches containing additive "A2", only one (with MOPLEN type PP) had softening effect, the others had no softening effect.

Masterbatches containing additive "A3" had higher MFI values than the polyolefins, so the additive "A3" could function as a plasticiser in the additive/polyolefin system. Additives in Braskem type PP caused drastic decrease in MFI, therefore not the plasticizing but other effect could be behind the trend.

\section{Methods}

\section{Sample Preparation}

Before sample preparation, hygroscopic raw materials were conditioned at least for $16 \mathrm{~h}$ at $60{ }^{\circ} \mathrm{C}$ in a drying oven to minimalized hydrolytic degradation. To achieve proper homogeneity of the samples, engineering thermoplastics were extrusion moulded by a laboratory twin screw extruder (LABTECH Engineering Company LTD LTE 20-44) adjusted with $1251 / \mathrm{min}$ screw speed. Moreover with the same extrusion screw speed films were produced by a twin screw extruder with a chill roll (LABTECH Engineering Company LTD LTE 20-40 and Chill Roll LCR300). After preparing blends samples were cut out for tensile tests. Length of samples were $12 \mathrm{~cm}$ for extruded samples, for films the width was $30 \mathrm{~mm}$, the length was $10 \mathrm{~cm}$. Average thickness of the films was $0.05 \mathrm{~mm}$. For rheological tests and MFI measurements extruded samples were pelletized. Masterbatches were produced by a two-roll mill (LabTech Engineering Ltd., LRM-100) at $140-180{ }^{\circ} \mathrm{C}$ and friction ratio was set to $32.8: 18.7$.

\section{Measurements}

As one of the essential requirements for polymers is their resistance to various stresses, therefore qualification on the basis of mechanical properties is indispensable. Mechanical properties of PET/engineering plastic blends were determined using tensile, rheological and MFI measurements. Tensile tests were carried out using an INSTRON 3345 universal tensile testing machine, on extruded strings with $90 \mathrm{~mm} / \mathrm{min}$, on films with $50 \mathrm{~mm} / \mathrm{min}$ crosshead speed under $55 \%$ relative humidity and at $21^{\circ} \mathrm{C} .11$ parallel measurements were carried out on extruded strings unconditioned and conditioned at $60{ }^{\circ} \mathrm{C}$ and $105^{\circ} \mathrm{C}$, and 7 parallel mesurements were accomplished in case of films on unconditioned samples and on samples conditioned at $60{ }^{\circ} \mathrm{C}$.

Rheological behavior of blends were investigated in the low shear rate range, between 2 and $3000 \frac{1}{s}$ or $2-10,000 \frac{1}{s}$ 
using a CEAST Smart RHEO 2000 capillary rheometer. The granulates were conditioned at $60^{\circ} \mathrm{C}$ for $4 \mathrm{~h}$ before the test. Rheological tests were executed under $275^{\circ} \mathrm{C}$ with $180 \mathrm{~s}$ or $360 \mathrm{~s}$ preheating time. Flow properties of the masterbatches and the extruded blends were also examined by MFI measurement in accordance with MSZ EN ISO:1133-2:2012. Structural changes of the blends as a result of the compatibilization of components and/or processing procedure were investigated by Fourier Transform infrared spectroscopy (Shimadzu IRTracer-100) with zinc selenide ATR crystal (Fig. 1).

\section{Results and Discussion}

\section{Properties of Blends Without Compatibilization}

Engineering thermoplastics in different compositions of PET/PC, PET/ABS and PET/PA systems was studied via tensile properties of specimens after conditioning at $60{ }^{\circ} \mathrm{C}$ and $105^{\circ} \mathrm{C}$ for $4 \mathrm{~h}$, moreover rheological tests and scanning electron microscopy (SEM) images were taken Figure 2.a illustrated the rheological behavior of PET/PC blends with 70\%, 60\% and 50\% PET-content. Shape of the viscosity curves of PET/PC blends revealed that the higher PET-content in the blend the more stable the viscosity curve. Viscosity curve of the sample with 50\% PET-content became unstable at a shear rate of about $50 \frac{1}{s}(\log 1.7)$, which may indicate molecular build-up or degradation, in the case of $60 \%$ PET-content, the curve became more unstable from about $200 \frac{1}{s}(\log 2.3)$ shear rate. In terms of the tensile properties, such as tensile strength, it was observed that all of the PET/PC specimens conditioned at $105^{\circ} \mathrm{C}$ had higher values than specimens after conditioning at $60{ }^{\circ} \mathrm{C}$ ("Appendix 5"). In contrast, the values of elongation at break were reversed, lower values were measured after conditioning at $105^{\circ} \mathrm{C}$, for example in the case of blend with $70 \%$ PET content the difference was circa 190\% (“Appendix 6").

Conditioning PET/ABS extruded strings at $105{ }^{\circ} \mathrm{C}$ resulted in higher tensile strength ("Appendix 7") furthermore the values improved as the PET content increased in blends. Elongation at break of PET/ABS blends ("Appendix 8") was much lower than that of PET/PC blends. In that case the effect of conditioning at higher temperature was not decisive on the elongation at break.

Considering viscosity curves of PET/ABS blends (Fig. 2b), the decrease of the viscosity curve of sample containing 70\% PET was the most intense, viscosity curves of blends with lower PET-content were more unstable.

Elongation at break of PET/PA samples (“Appendix 9") improved with increasing PET content if conditioning at $60{ }^{\circ} \mathrm{C}$. That tendency towards tensile strength ("Appendix 10") cannot be determined. Viscosity curves of PET/ PA blends (Fig. 2c), showed decreasing dynamic viscosity with a decrease in PET-content. Drastic decrease in the elongation at break was measured after conditioning at higher $\left(105^{\circ} \mathrm{C}\right)$ temperature. That was probably due to the spontaneous recrystallization of PET above $70{ }^{\circ} \mathrm{C}$ causing the specimens to loose their elasticity. Thus, it was concluded that the crystallinity of PET dominated in the blends after conditioning at $105^{\circ} \mathrm{C}$, but the degree of miscibility was decisive after conditioning at $60^{\circ} \mathrm{C}$.

All in all, after conditioning the specimens at two temperatures, tensile strength and elongation at break of the several composition of PET/PC blends were proved to be more advantageous comparing to PET/PA and PET/ABS blends.
Fig. 1 MFI values of masterbatches with different additive concentration $(0.1 \%, 0.2 \%$, $0.5 \%)$ with distinct types of matrix materials

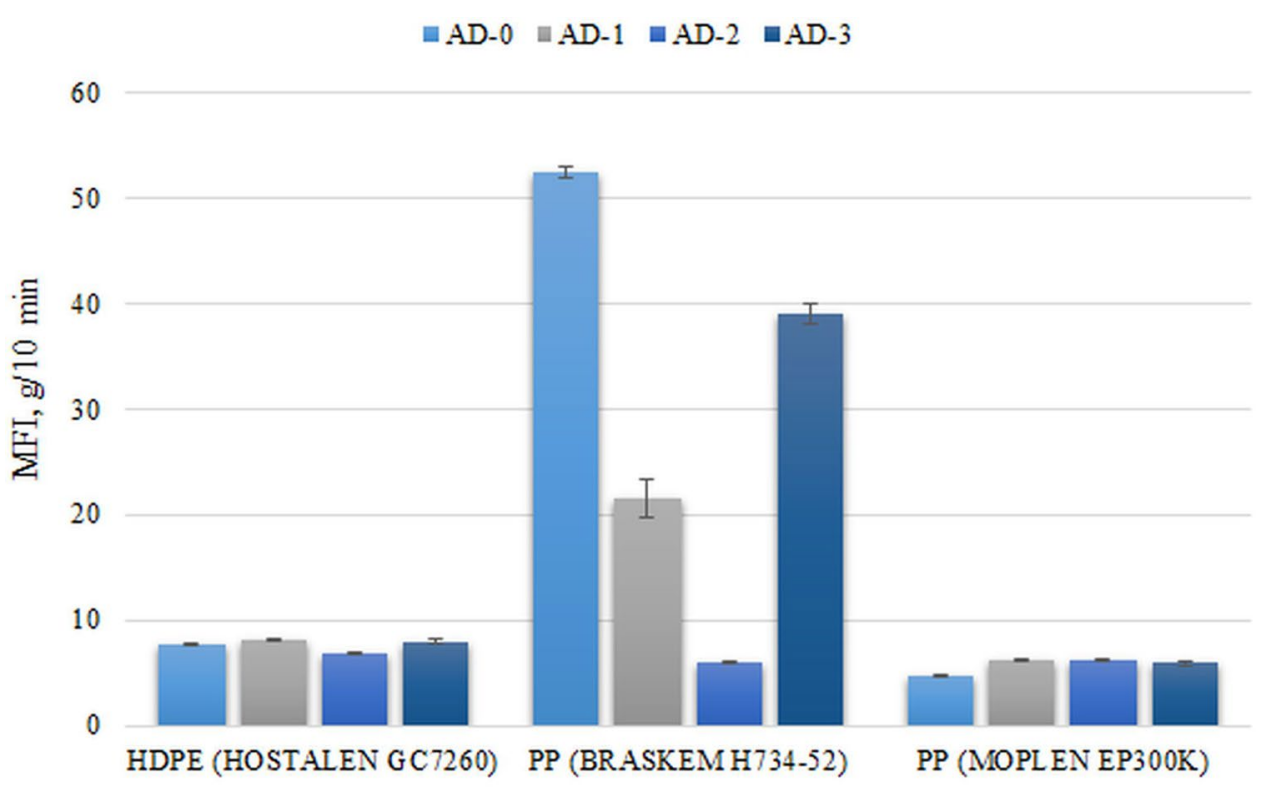



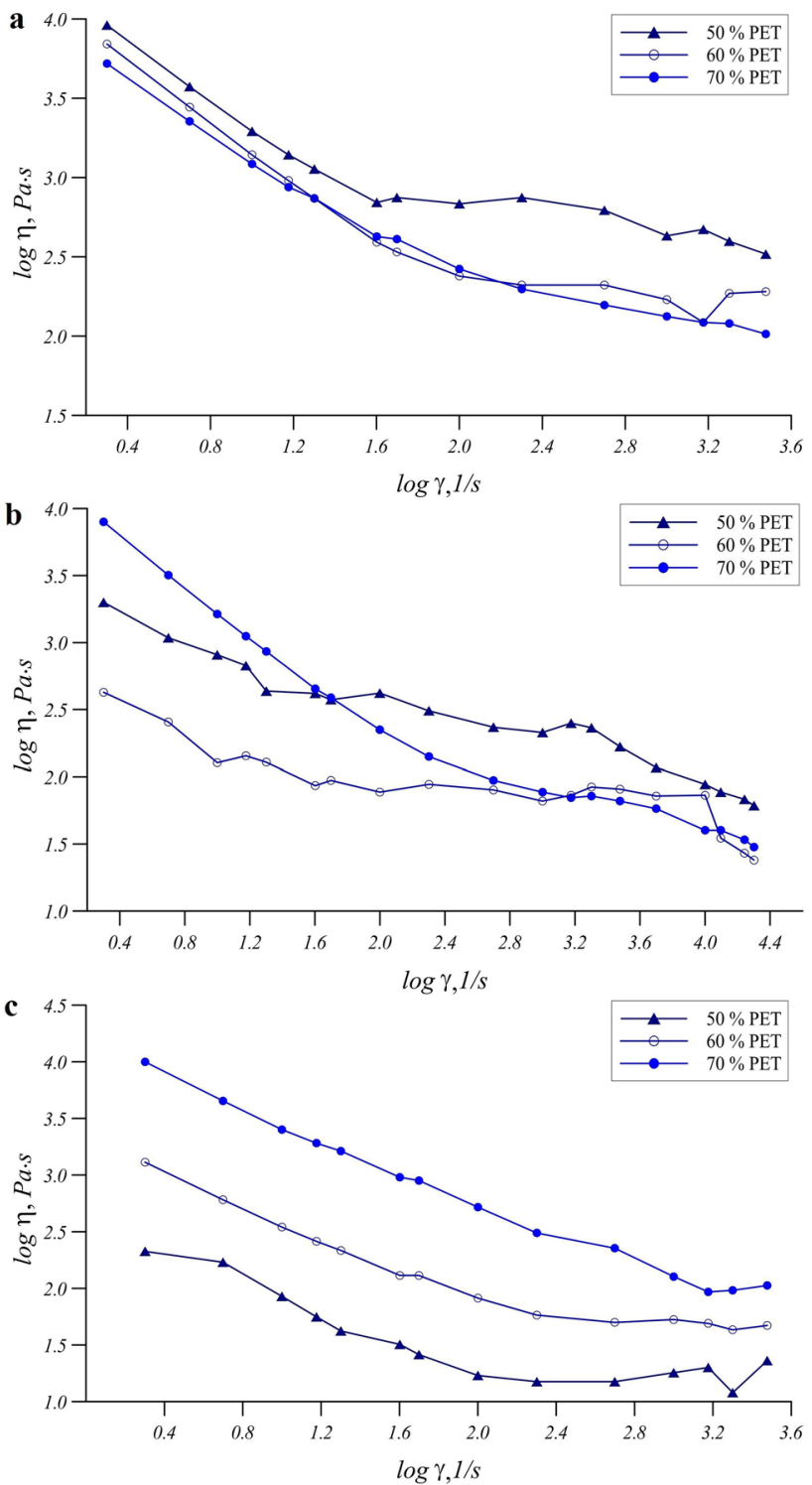

Fig. 2 Viscosity curves of PET/PC (a), PET/ABS (b) and PET/PA (c) blends containing $50 \%, 60 \%$ and $70 \%$ PET at $275^{\circ} \mathrm{C}$

PET/ABS and PET/PA blends performed unfavorably not only in tensile strength but also in elongation at break. Comparing rheological results of PET/PA, PET/ABS and PET/ PC, the shape of viscosity curves of the blends with higher PET content (70\%) was found to be the most stable. For the other composition, greater or lesser changes were observed in the test range, which could mean degradation or structure buildings from reactions between the two components or/and the accompanying components of blends. All of the three engineering thermoplastics examined with PET indicated only a limited degree of miscibility in the blends that was supported by SEM images (Fig. 3), because separation of matrix and disperse phases appeared. In terms of morphology, only PET/PA showed a fibrous structure related to

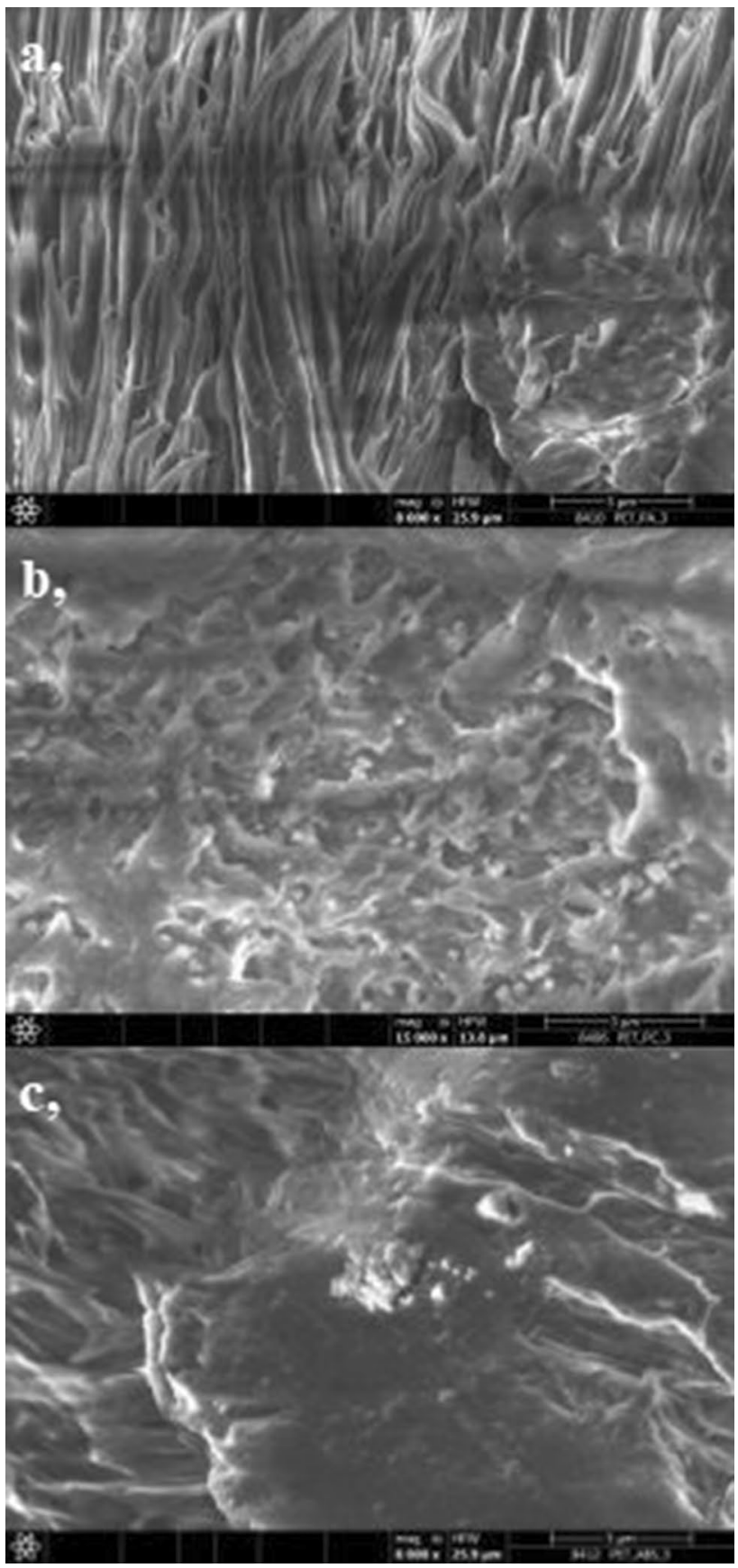

Fig. 3 SEM images of 70/30 PET/PA blend (a), PET/PC blend (b) and PET/ABS blend (c)

blends of PET/PC and PET/ABS in case of the same PET content. The phases are roughly separated from each other in the case of all three blends, therefore, it can be stated that the morphological structure was not homogeneous. The main aim of the compatibilization is to make the morphology smoother and more uniform structure after the addition of the additive, since as long as the surface is not uniform and phase separation is presented, the blend shows weak 
adhesion, improvement in mechanical properties cannot be achieved.

Infrared spectroscopy was used to compare the effect of addition of different types of engineering plastics on the typical stretching vibrations of PET. For comparison $3000-2800 \mathrm{~cm}^{-1}$ wavenumber range (Fig. 4) was investigated, asymmetric stretching vibrations of methyl and methylene groups appeared at $2967 \mathrm{~cm}^{-1}$ and $2920 \mathrm{~cm}^{-1}$, respectively, besides symmetric stretching vibration of methylene group at $2851 \mathrm{~cm}^{-1}$ [21]. Ratio of $\mathrm{CH}_{2} / \mathrm{CH}_{3}$ belonging to the typical wavenumbers were calculated to be $0.03,4.85$ and 1.48 for $50 \%$ ABS, PC and PA respectively. The sequence of the ratio was as expected based on the monomer composition of the different types.

\section{PET/PA Blends}

The effects of compatibilizing additives were investigated in blends containing waste PET with polyolefin impurities might be originated from cap or label of the bottles. Three different types of experimental olefin-maleic-anhydride copolymer based additives and a commercial one (LICOMONT AR504) were used to improve the miscibility of PET and PA. Olefin-maleic-anhydride copolymer based additives were added to the blends in the form of a masterbatch. Matrix materials of masterbatches were two types of polypropylene (BRASKEM H734-52 and MOPLEN EP300K) and the other was a high density polyethylene (HOSTALEN GC7260). Because the commercial additive was available in powder form, it was easy to add in small amounts to the blends, so there was no need for preparing a masterbatch. The characteristics of four different compositions (90/10, 80/20, 20/80 and 10/90) of PET/PA blend are presented without and in the presence of compatibilizing additives.

First of all the tensile properties of blends without any compatibilizing additives were investigated since the polyolefin contamination can modify the characteristics of PET blends. Figure 5 illustrated the values of tensile modulus and elongation at break of specimens in the case of three different conditioning temperature $\left(25^{\circ} \mathrm{C}, 60^{\circ} \mathrm{C}\right.$ and $\left.105^{\circ} \mathrm{C}\right)$. It can be highlighted that the rigidity was persisted for specimens conditioned at $105{ }^{\circ} \mathrm{C}$ so the polyolefin impurities did not change anything in spontaneous recrystallization. Conditioning at $60{ }^{\circ} \mathrm{C}$ was also affected slightly the rigidity of specimens. That trend could be monitored very well through the values of tensile modulus and elongation at break, namely elongation at break of specimens decreased continuously with increasing temperature of conditioning.

The plasticizing effect of additive can be seen in the values of elongation at break in the case of three composition of PET/PA (90/10, 80/20 and 20/80). Comparing tensile properties of 80/20 PET/PA blends containing PP (MOPLEN EP300K) and HDPE (HOSTALEN GC7260) based masterbatch, there were differences measured, circa $160 \mathrm{MPa}$ in

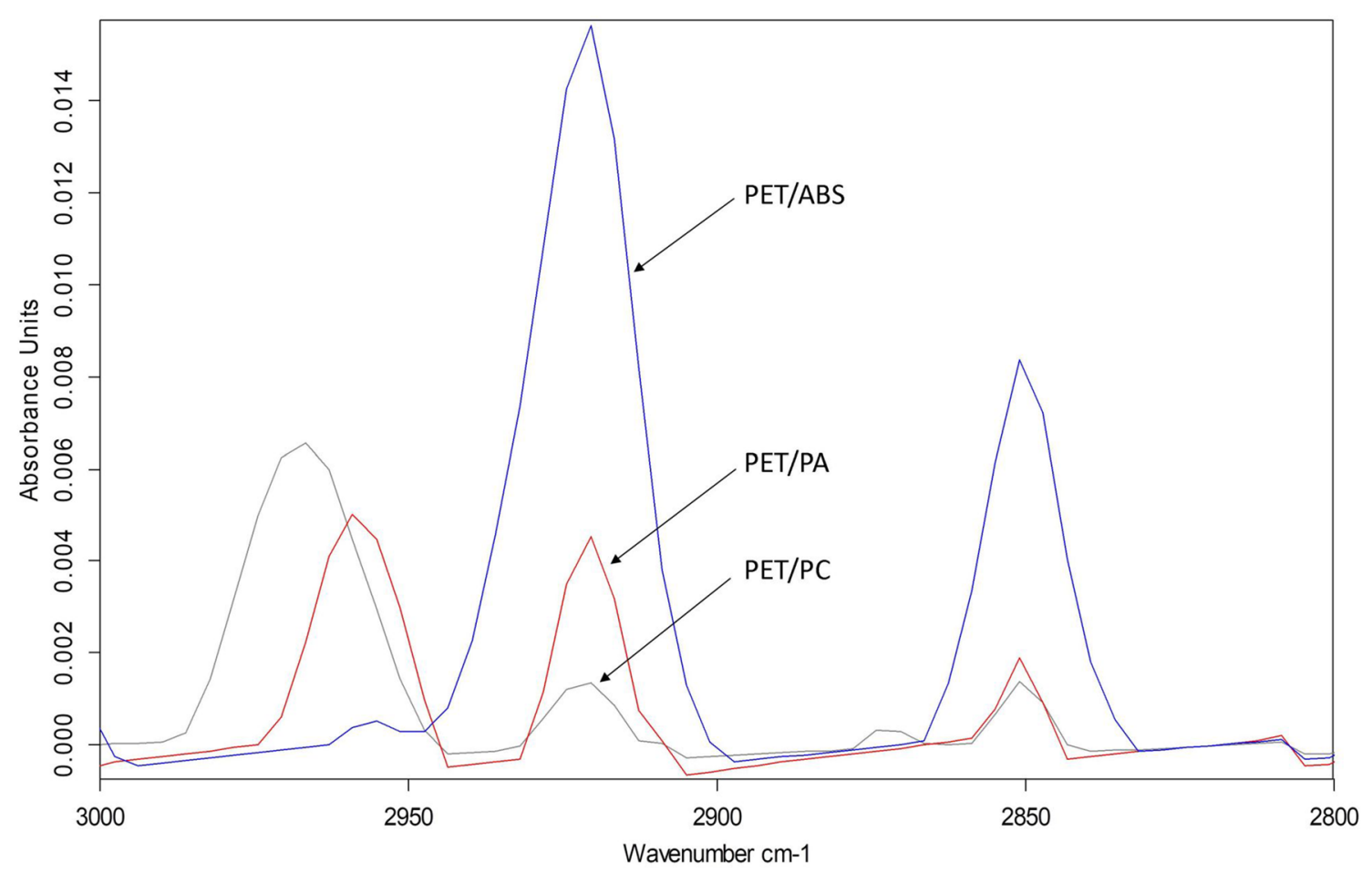

Fig. 4 FT-IR spectra of PET/ABS, PET/PA and PET/PC containing 50\% PET between the wavenumber range of $2800 \mathrm{~cm}^{-1}$ and $3000 \mathrm{~cm}^{-1}$ 
Fig. 5 Tensile modulus and elongation at break of PET/PA in the case of three different conditioning temperature

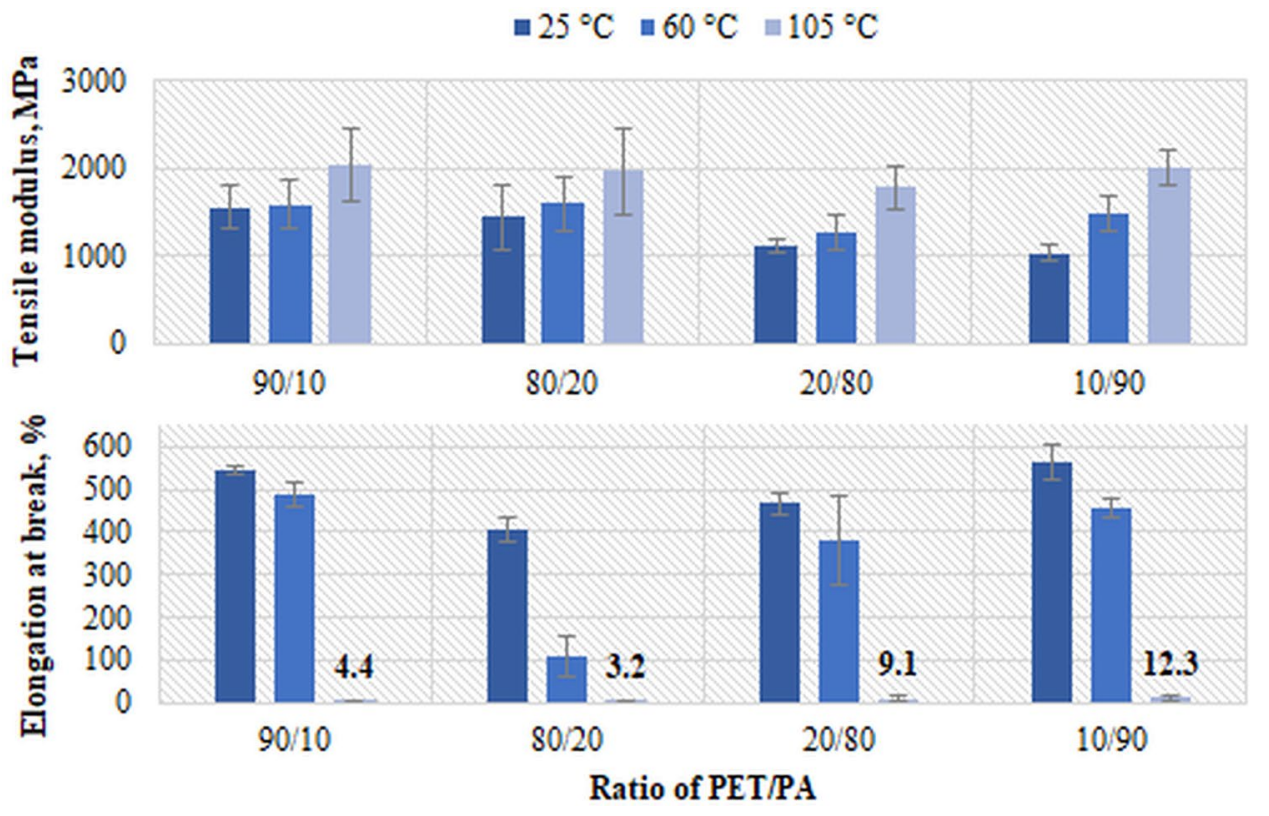

tensile modulus and about $25 \%$ differences in elongation at break. Figure 6 illustrated tensile properties of blends with additive "A2" containing the three different types of matrix material in the masterbatches.

Three types of olefin-maleic-anhydride copolymer based additives were investigated incorporated into the MOPLEN EP300K matrix before extrusion with PET and PA. Influence of additives was dependent on the composition of PET/PA ("Appendix 11"). For instance the additive "A3" had the most unfavourable effect on the $90 / 10$ blend, whereas it was the most advantageous in the case of 10/90 PET/PA blend. For elongation at break additive "A2" performed well in compositions of 90/10, 80/20 and 20/80. In either case, additive "A1" had no advantageous effect on tensile properties with the exception of tensile strength of 80/20 composition.

80/20 and 20/80 PET/PA were chosen to the investigation of effects of compatibilizer concentration $(0.1 \%, 0.2 \%, 0.5 \%)$ in the masterbatch on the mechanical properties. Viscosity of only the masterbatch containing the highest (5\%) additive concentration increased (Table 2), thus it did not show any
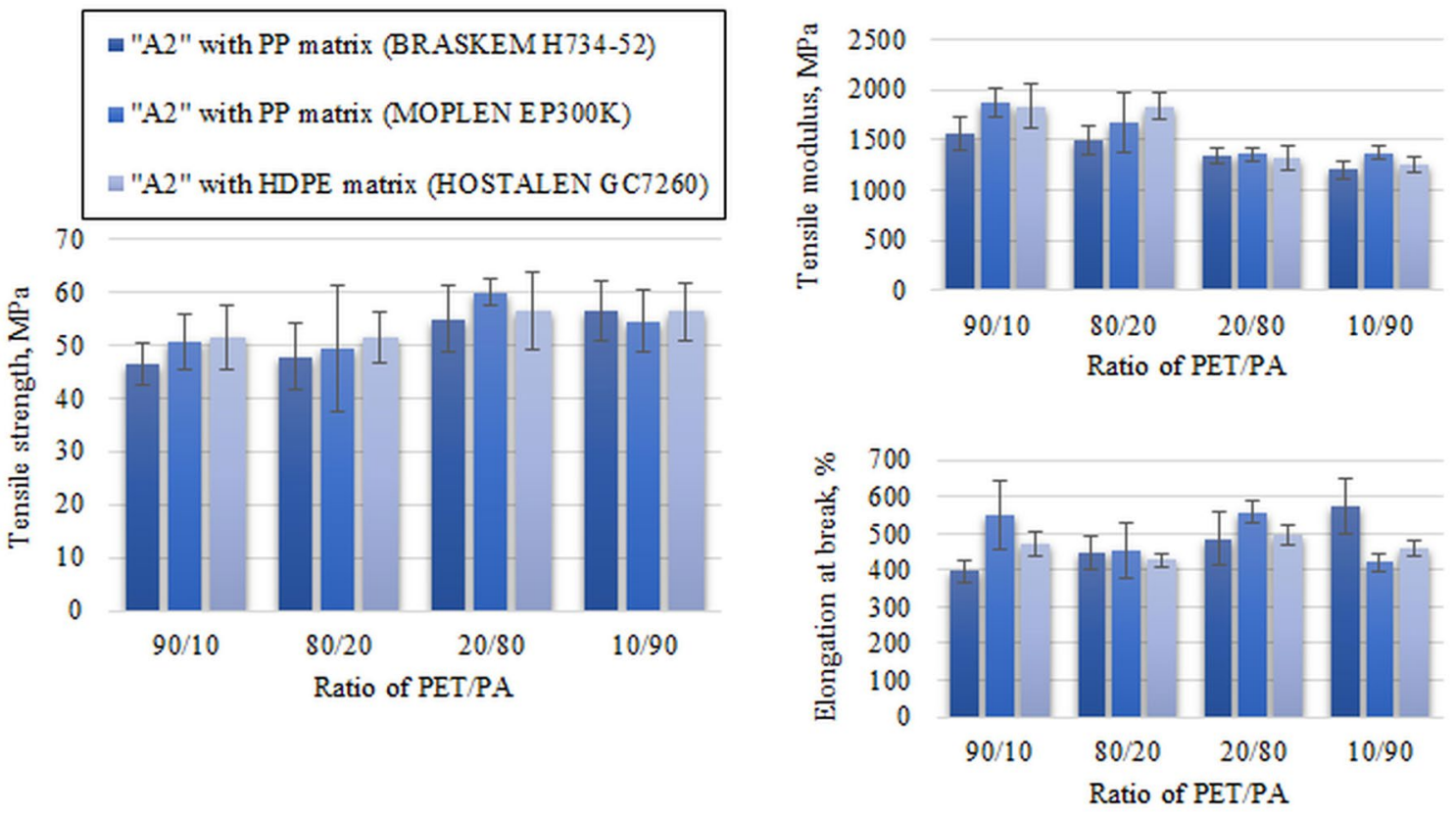

Fig. 6 Tensile properties of PET/PA blends with additive "A2" containing three different types of matrix material 
Table 2 MFI values of masterbatches containing "A2" additive with PP (MOPLEN EP300K) matrix material Additive concentra- $\mathrm{MFI}, \frac{g}{10 \mathrm{~min}}$
tion, $\%$

\begin{tabular}{ll}
\hline 0 & $4.8 \pm 0.1$ \\
1 & $7.1 \pm 0.1$ \\
2 & $6.2 \pm 0.1$ \\
5 & $3.3 \pm 0.1$ \\
\hline
\end{tabular}

plasticizing effect, but masterbatches containing $1 \%$ and $2 \%$ additive had a reduced viscosity, therefore increased MFI compared to neat polypropylene.

Tensile strength was adversely influenced by additive concentrations of $0.1 \%$ and $0.5 \%$, moreover, lower tensile strength were measured not only compared to the blends with $0.2 \%$ additive, but values also decreased compared to the blend without additive however standard deviation was

Without additive $\quad 0.1 \%$ additive $\quad 0.2 \%$ additive $\quad 0.5 \%$ additive $\quad 0.2 \%$ commercial additive
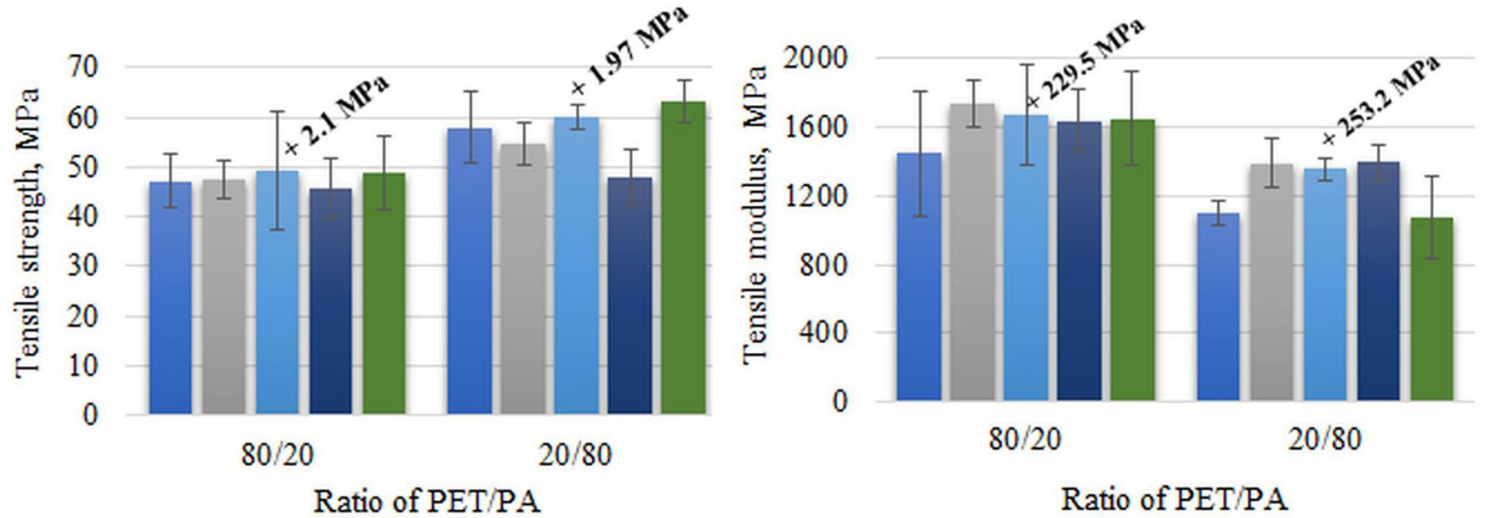

Fig. 7 Tensile strength and tensile modulus of 80/20 and 20/80 PET/PA blends

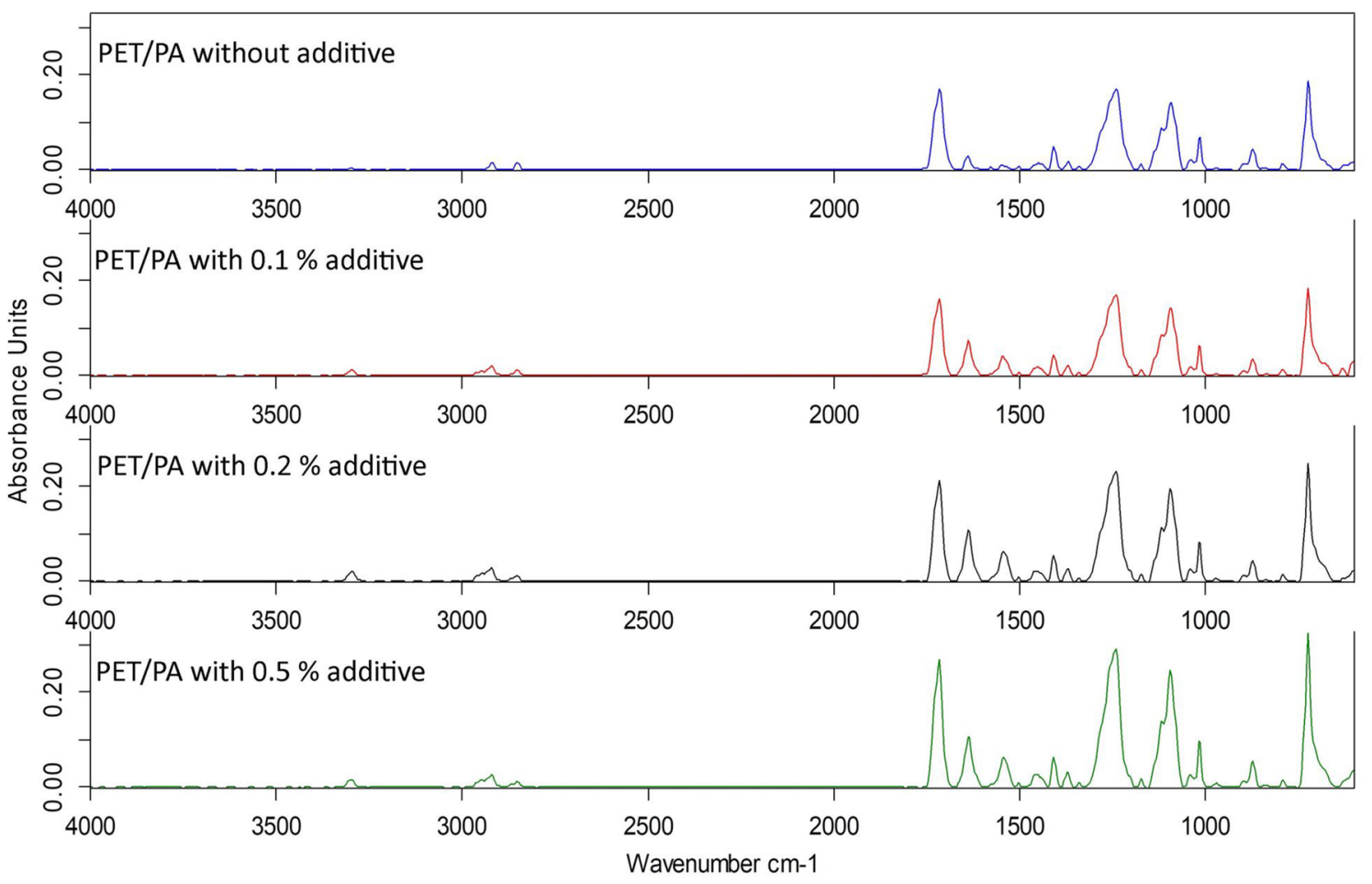

Fig. 8 FT-IR spectra of PET/PA blends without and with masterbatch containing PP matrix material between the wavenumber range $4000 \mathrm{~cm}^{-1}$ and $600 \mathrm{~cm}^{-1}$ 
not negligible. In the case of 80/20 PET/PA composition, additive concentration absolutely had no effect, $0.2 \%$ additive showed only a slight improvement. Additive concentration had a greater effect on the tensile strength in the case of 20/80 PET/PA blend, the most preferred concentration was $0.2 \%$. Thus, considering the three additive concentrations, using additive "A2" in $0.2 \%$ concentration was regarded the most favourable for developing tensile strength in the presence of MOPLEN EP300K polypropylene as matrix in the masterbatch. In terms of tensile modulus, the effect of a masterbatch containing $0.1 \%$ additive was found to be the most favourable, however effectiveness of higher additive concentrations only slightly differed. In regard to the elongation at break significantly lower value was measured in the case of 20/80 PET/PA composition in the presence of $0.5 \%$ additive compared to the blend containing $0.2 \%$ additive and the additive free blend.

All in all, the additive "A2" was advantageously used in the $0.2 \%$ concentration both in $80 / 20$ and $20 / 80$ PET/PA blends (Fig. 7), since it had the most favourable influences on tensile strength and on elongation at break among the three concentrations studied. FT-IR spectra of 80/20 PET/PA blend showed differences in the ratio of some peaks (Fig. 8). Between $3000 \mathrm{~cm}^{-1}$ and $2800 \mathrm{~cm}^{-1}$ wavenumber range, asymmetric stretching vibrations of methyl and methylene groups appeared at $2947 \mathrm{~cm}^{-1}$ and $2920 \mathrm{~cm}^{-1}$, respectively, besides symmetric stretching vibration of methylene group at $2851 \mathrm{~cm}^{-1}$. Table 3 summarized ratio of $\mathrm{CH}_{2} / \mathrm{CH}_{3}$ belonging to the typical wavenumbers.

Peaks did not appear at $2920 \mathrm{~cm}^{-1}$ and $2947 \mathrm{~cm}^{-1}$ in the case of blend without additive, for blends containing masterbatches, the $\mathrm{a} / \mathrm{b}$ ratios were decreased with increasing additive concentration. Ratio of e/f increased with increasing additive concentration, changes of $\mathrm{c} / \mathrm{d}$ ratio was not remarkable.

Peaks of methyl functional groups did not appear in the spectrum of additive-free blend, therefore, ratio of methylene and methyl groups could not be calculated. The ratio of

Table 3 Ratio of functional groups in the case of 80/20 PET/PA blends with different additive concentrations

\begin{tabular}{llllr}
\hline Blend composition & $\begin{array}{l}\text { Additive con- } \\
\text { centration, } \%\end{array}$ & \multicolumn{3}{c}{ Ratio of functional groups } \\
\cline { 3 - 5 } & & $\frac{a}{b}(1)$ & $\frac{c}{d}(2)$ & $\frac{e}{f}(3)$ \\
\hline 80/20 PET/PA & - & - & 9.1 & 49.9 \\
80/20 PET/PA & 0.1 & 2.0 & 6.0 & 44.5 \\
80/20 PET/PA & 0.2 & 1.7 & 5.4 & 96.6 \\
80/20 PET/PA & 0.5 & 1.6 & 6.5 & 231.9
\end{tabular}

$\frac{a}{b}=\frac{2920 \mathrm{~cm}^{-1}}{2947 \mathrm{~cm}^{-1}}$
$\frac{c}{d}=\frac{1640 \mathrm{~cm}^{-1}}{3298 \mathrm{~cm}^{-1}}$
$\frac{e}{f}=\frac{1717 \mathrm{~cm}^{-1}}{1759 \mathrm{~cm}^{-1}}$ methylene and methyl groups changed with additive concentration in the blends. Ratio of amide type functional groups had the highest value in the additive free sample as expected. In the presence of additives $30 \%$ lower ratio was calculated than for additive-free samples and due to the amide content ratio slightly changed with additive concentration. The two different types of carbonyl stretching vibration shifted by additive introduction, ratio of the vibrations increased with additive concentration in the samples.

Further studies were carried out to investigate the effect of additive concentrations, whereby the rheological behaviour of the blends were measured by a capillary rheometer. In terms of viscosity curves of 80/20 composition dynamic viscosity of the additive free sample was the lowest up to $50 \frac{1}{5}(\log (\gamma)=1.7)$, the viscosity of the sample containing $0.2 \%$ and $0.5 \%$ additive was slightly higher, the highest viscosity was represented by the blend produced with the lowest concentration of additive. Excepting additive free sample, blends showed smaller or larger instability in each case from shear rate of $1500 \frac{1}{s}(\log (\gamma)=3.18)$.

The instability of the curves, as well as the higher viscosity of the blends containing $0.1 \%$ and $0.5 \%$ additive, could suggest that molecular structure build-ups might took place as a result of the compatibilizing effect.
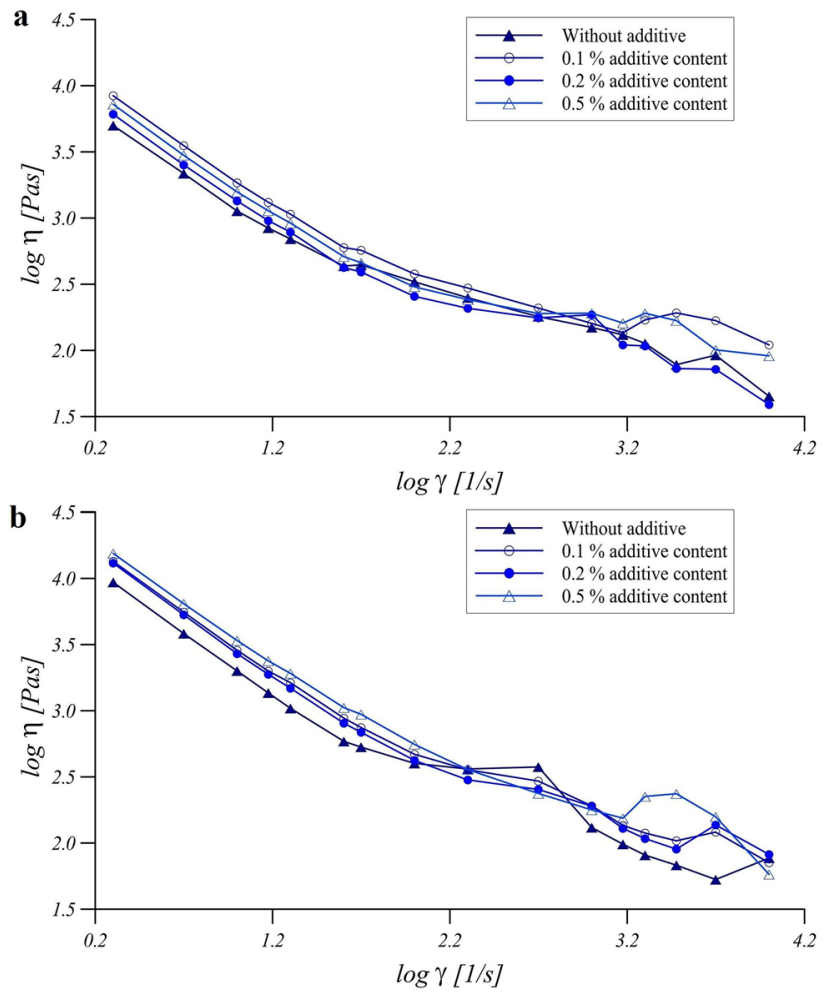

Fig. 9 Comparison of the effect of additive concentration on rheological behaviour of PET/PA blends containing $80 \%$ PET (a) and containing $80 \% \mathrm{PA}(\mathbf{b})$ at $270{ }^{\circ} \mathrm{C}$ 
Viscosity curves of blend containing $80 \%$ polyamide became more stable by the addition of the compatibilizer, the blends containing the $0.1 \%$ and $0.2 \%$ additive showed the most stable curve.

Higher viscosity increase was observed in the presence of the highest $(0.5 \%)$ additive concentration (Fig. 9) in the $1500-3000 \frac{1}{s}(\log (\gamma)=3.18-3.48)$ shear rate range, which could be a sign of the build-up by compatibility. Achieving a shear rate of $3000 \frac{1}{s}(\log (\gamma)=3.48)$, a noticeable protrusion can be seen in the curve of blends containing $0.1 \%$ and $0.2 \%$, due to the aforementioned compatibility.

In the shear rate range of $2-10,000 \frac{1}{s}(\log (\gamma)=0.3-4)$, on average, the blend containing $0.2 \%$ additive (Fig. 9) had a lower dynamic viscosity among the two most stable curves, which is considered to be more advantageous in terms of processing the polymer blend.

SEM images of 80/20 and 20/80 PET/PA blends with $0.2 \%$ additive and without it are presented in Fig. 10.
Morphology of the undoped sample differs slightly contrasted to the sample containing masterbatch comparing undoped and doped PET/PA blends with a composition of $80 / 20$ (Fig. 10a, b). It can be seen that there is more of the dispersed part in the matrix resulting in a less finer morphology. The PET/PA sample containing additive shows more homogeneous structure, there are fewer dispersed parts in the image. Considering the SEM images of PET/PA with 20/80 composition, phase separation can be noted in case of additive-free blend. Small spherical dispersed parts are observed in the matrix, which may also indicate polyolefin contaminants of PET. The less homogeneous surface shows weak adhesion between phases. In case of the blend made with the addition of masterbatch, a more fibrous structure were developed, spherical parts cannot be found, the morphological structure is more homogeneous. Morphology became more homogeneous as a result of the addition of compatibilizers, less dispersed phases can be separated for
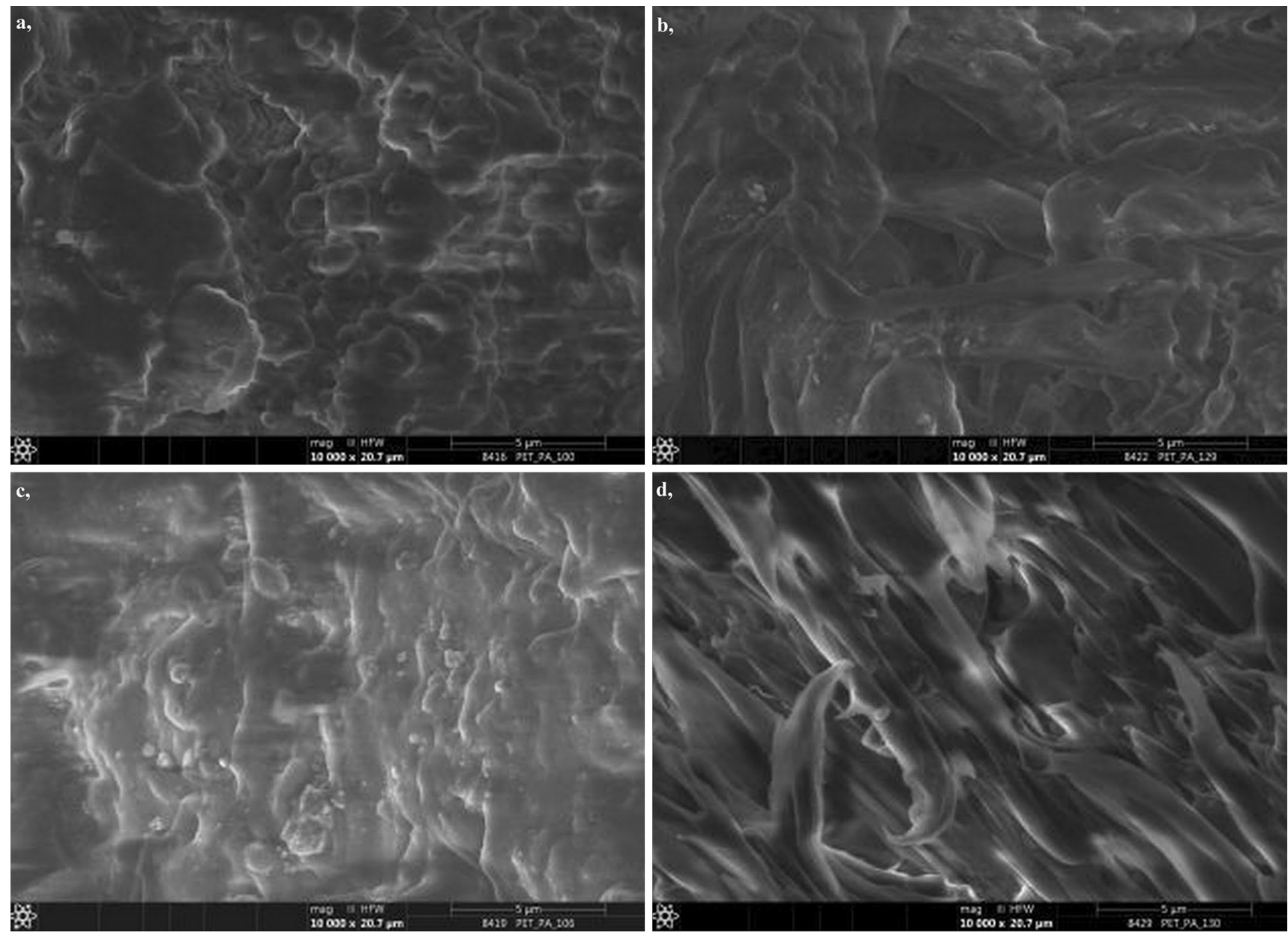

Fig. 10 SEM images of 80/20 PET/PA blend without compatibilizer (a) and with masterbatch containing $0.2 \%$ compatibilizing additive (b), furthermore SEM images of 20/80 PET/PA blend without compatibilizer (c) and with masterbatch containing $0.2 \%$ compatibilizing additive (d) 
both PET/PA compositions. As a conclusion the results of mechanical properties were confirmed by SEM images.

\section{Conclusion}

In that research mechanical properties of PET blends with ABS, PC and PA were investigated in the form of extruded strings. Waste PET was investigated for environmental reasons, one was a real industrial waste based PET regranulate containing polyolefin impurities coming from cap and label of PET bottles, the other waste material was selectively collected PET bottles without any polyolefins. Mechanical and rheological properties of the blends indicated limited miscibility between the components that was also confirmed by SEM images showing the separation of dispersed and matrix phases. Consequently, a sufficient compatibilization was essential, therefore the effect of three different types of experimental compatibilizing additives were studied in various compositions of PET blends. The differences in the additive structures were manifested in the ratios of the anhydride, half-ester, ester-amide and imide functional groups. Experimental additives were used in the form of masterbatches with different types of polyolefins as matrix materials for easier processing. Influences of matrix materials on the additive efficiency were studied in two types of polypropylene and in a high density polyethylene. The experimental "A2" marked olefin-maleic-anhydride copolymer based additive with high ratio of nitrogen containing functional groups with polypropylene (MOPLEN EP300K) matrix showed favourable effect on mechanical properties. With the advantageous masterbatch, extruded strings in composition of 80/20 and 20/80 PET/PA showed beneficial properties regardless of conditioning, in addition to their excellent elongation at break, improvements in both tensile strength and tensile modulus were observed. The blends have been examined using three different additive concentrations $(0.1 \%, 0.2 \%$ and $0.5 \%$ ) with PP matrix material, among them $0.2 \%$ additive concentration was proved to be the most effective. Hence, it was managed to produce an additive structure which could be effective in extruded blends with both higher waste PET content and higher PA content.

Funding Open access funding provided by University of Pannonia.

Open Access This article is licensed under a Creative Commons Attribution 4.0 International License, which permits use, sharing, adaptation, distribution and reproduction in any medium or format, as long as you give appropriate credit to the original author(s) and the source, provide a link to the Creative Commons licence, and indicate if changes were made. The images or other third party material in this article are included in the article's Creative Commons licence, unless indicated otherwise in a credit line to the material. If material is not included in the article's Creative Commons licence and your intended use is not permitted by statutory regulation or exceeds the permitted use, you will need to obtain permission directly from the copyright holder. To view a copy of this licence, visit http://creativecommons.org/licenses/by/4.0/.

\section{References}

1. Evstatiev, M., Nicolov, N., Fakirov, S.: Morphology of microfibrillar reinforced composites PET/PA6 blend. Polymer (1996). https ://doi.org/10.1016/0032-3861(96)00137-1

2. Sui, X., Xie, X.-M.: Creating super-tough and strong PA6/ABS blends using multi-phase compatibilizers. Chin. Chem. Lett. (2019). https://doi.org/10.1016/j.cclet.2018.04.035

3. Subramanian, M.N.: Polymer Blends and Composites: Chemistry and Technology. Scrivener Publishing LLC, Beverly (2017)

4. Utracki, L.A.: Polymer Blends Handbook. Kluwer Academic Publishers, Dordrecht (2002)

5. Plastics-the Facts. https://www.plasticseurope.org/en/resources/ publications/1804-plastics-facts-2019 (2019). Accessed 26 Feb 2020

6. Maris, J., Bourdon, S., Brossard, J.-M., Cauret, L., Fontaine, L., Montembault, V.: Mechanical recycling: compatibilization of mixed thermoplastic wastes. Polym. Degrad. Stab. (2018). https ://doi.org/10.1016/j.polymdegradstab.2017.11.001

7. PlasticsEurope, Annual Review 2017-2018. https://www.plast icseurope.org/en/resources/publications/498-plasticseurope-annua 1-review-2017-2018. Accessed 26 Feb 2020

8. Navarro, R., Ferrandiz, S., Lopez, J., Seguí, V.J.: The influence of polyethylene in the mechanical recycling of polyethylene terephtalate. J. Mater. Process. Technol. (2008). https://doi.org/10.1016/j. jmatprotec.2007.04.126

9. Al-Sabagh, A.M., Yehia, F.Z., Eshaq, Gh, Rabie, A.M., ElMetwally, A.E.: Greener routes for recycling of polyethylene terephthalate. Egypt. J. Pet. (2015). https://doi.org/10.1016/j. ejpe.2015.03.001

10. Zhang, Z., Wang, C., Mai, K.: Reinforcement of recycled PET for mechanical properties of isotacticpolypropylene. Adv. Ind. Eng. Polym. Res. (2019). https://doi.org/10.1016/j.aiepr .2019.02.001

11. Wang, D., Yang, B., Chen, Q.-T., Chen, J., Li-Fen, Su, Chen, P., Zheng, Z.-Z., Miao, J.-B., Jia-Sheng Qian, Ru, Xia, Y.S.: A facile evaluation on melt crystallization kinetics and thermalproperties of low-density polyethylene (LDPE)/Recycled polyethyleneterephthalate (RPET) blends. Adv. Ind. Eng. Polym. Res. (2019). https://doi.org/10.1016/j.aiepr.2019.05.002

12. Kalfoglou, N.K., Skafidas, D.S., Kallitsis, J.K.: Blends of poly(ethylene terephtalate) with unmodified and maleic anhydride grafted acrylonitrile-butadiene-styrene terpolymer. Polymer (1996). https://doi.org/10.1016/0032-3861(96)88486-2

13. Fox, B., Moad, G., van Diepen, G., Willing, I., Cook, W.D.: Characterization of poly(ethylene terephtalate) and poly(ethylene terephtalate) blends. Polymer (1997). https://doi. org/10.1016/S0032-3861(96)00872-5

14. Wellen, R.M.R., Canedo, E.L.: Complex cold crystallisation peaks in PET/PS blends. Polym. Test. (2015). https://doi. org/10.1016/j.polymertesting.2014.09.020

15. Ferreira, C.T., Perez, C.A.B., Hirayama, D., Saron, C.: Recycling of polyamide (PA) from scrap tires as composites and blends. J. Environ. Chem. Eng. (2013). https://doi.org/10.1016/j. jece.2013.07.016

16. Thodsaratpreeyakul, W., Uawongsuwan, P., Negoro, T.: Properties of recycled-polyethylene terephtalate/polycarbonate blend 
fabricated by vented barrel injection molding. Mater. Sci. Appl. (2018). https://doi.org/10.4236/msa.2018.91012

17. Pesetskii, S.S., Filimonov, O.V., Koval, V.N., Golubovich, V.V.: Structural features and relaxation properties of PET/PC blends containing impact strength modifier and chain extender. Exp. Polym. Lett. (2009). https://doi.org/10.3144/expresspolymlet t.2009.76

18. Venkatachalam, S., Nayak, S.G., Labde, J.V., Gharal, P.R., Rao, K., Kelkar, A.K.: Degradation and recyclability of poly(ethyleneterephthalate). In: El-Din, H., Saleh, M. (eds.) Polyester, pp. 76-98. IntechOpen, London (2012)

19. Arrighi, V., Cowie, J.M.G., Fuhrmann, S., Youssef, A.: Miscibility criteria in polymer blends and its determination. In: Isayev, A.I. (ed.) Encyclopedia of Polymer Blends: Volume 1: Fundamentals. Wiley, Hoboken (2010)
20. Simon-Stőger, L., Varga, C.S., Greczula, E., Nagy, B.: A journey into recycling of waste elastomers via a novel type of compatibilizing additives. Express Polym. Lett. (2019). https://doi. org/10.3144/expresspolymlett.2019.37

21. Chalmers, J.M.: Infrared spectroscopy in analysis of polymers and rubbers. In: Meyers, R.A. (ed.) Encyclopedia of Analytical Chemistry: Applications. Theory and Instrumentation, Wiley, New York (2006)

Publisher's Note Springer Nature remains neutral with regard to jurisdictional claims in published maps and institutional affiliations. 